\title{
Effect of Type of Degraded DNA Samples on Human Eye Color Prediction
}

\author{
Dilara Devranoglu, Ilksen Tavaci, Gonul Filoglu and Ozlem Bulbul* \\ Institute of Forensic Science, Istanbul University-Cerrahpasa, Istanbul, Turkey
}

\begin{abstract}
A B S T R A C T
Single nucleotide polymorphisms (SNPs) are the most abundant genetic markers in the human genome. SNPs are used in forensics for predicting the externally visible characteristics of a given individual based on a sample of DNA alone. In this study, we tested degraded DNA samples to determine the eye color prediction accuracy of the IrisPlex system. We used five years old bloodstains and UVC exposed (30 and $60 \mathrm{~min}$ ) DNA samples. PCR and electrophoresis were performed. The multinomial logistic regression model statistics is applied for eye color prediction. We observed allele and locus drop-outs on both bloodstains stored for five years and UVC exposed samples. The brown and blue eye colors were correctly predicted for reference and degraded samples. The intermediate eye colors were predicted to be brown or inconclusive. The degradation by aging bloodstains or UVC exposure, is differently affected the prediction accuracy depending on the informativeness of the SNPs. This study showed that the prediction of the eye color is highly accurate for the blue and brown eye colored individuals. However, the IrisPlex prediction accuracy could be influenced by the old and degraded samples.
\end{abstract}

Article Information

Received 10 March 2020

Revised 14 May 2020

Accepted 30 May 2020

Available online 12 April 2021

Authors' Contribution

DD, GF and OB designed the study. DD and IT performed the experiments. DD, IT and $\mathrm{OB}$ were involved in the data analysis. $O B$ supervised the study and wrote the manuscript. GF gave critics during the preparation of the manuscript.

Key words

Forensic genetics, SNP, Eye color, IrisPlex, Degradation, Phenotype, UVC

\section{INTRODUCTION}

$I^{\prime}$ n current forensic casework, conventional short tandem repeats (STRs) analysis is typically used for identification of the biological evidence. However, STRs are insufficient when STR profile does not match any of the known suspect's profile or any of the profile from a criminal DNA database, thus in the case of a non-match, the investigation would go unsolved. With advances in genetic knowledge and technologies alternative DNA analysis systems could provide valuable information from the DNA evidence (Budowle and van Daal, 2008; Kayser and Schneider, 2009; Kayser, 2015). Forensic DNA intelligence, also as known as forensic DNA phenotyping (FDP), provides information regarding the biogeographical ancestry (BGA) and externally visible characteristics (EVCs) of unknown DNA sample donor. Forensic DNA intelligence tools can aid investigators by providing physical appearance of the suspect and therefore the potential suspect pool could be narrowed down. Forensic DNA intelligence can also be applied in identifying mass disaster victims, missing person cases and in anthropological studies. Thus forensic DNA intelligence has flourished as a powerful informative tool in criminal investigations

\footnotetext{
Corresponding author: ozlem.bulbul@istanbul.edu.tr; ozlembulbul00@gmail.com 0030-9923/2021/0004-1201 \$ 9.00/0

Copyright 2021 Zoological Society of Pakistan
}

(Kayser and de Knijff, 2011; Kayser, 2015; Mehta et al., 2017).

In order to predict the appearance of the unknown individual, the forensic scientists have started following the genome-wide association studies (GWAS) that include finding genes for human complex traits such as eye, hair and skin color, pigmentation-related traits such as freckles, baldness, age, hair morphology, body height (Shriver et al., 2003; Sulem et al., 2007; Sturm, 2009; Visser et al., 2012; Liu et al., 2014, 2015; Kayser, 2015; Toom et al., 2016; Chaitanya et al., 2017; Walsh et al., 2017; Pospiech et al., 2018).

The first human complex trait studies indicate that HERC2/OCA2 genes are responsible for the most of the blue and brown eye color inheritance (Frudakis et al. 2007; Donnelly et al. 2012). A single promotor SNP rs12913832 in $H E R C 2$ gene is discovered to be strongly associated with blue or brown eye color variations (Visser et al., 2012). The other genes (SLC2A4, TYR, TYRP1, SLC45A2, and $I R F 4$ ) have also been identified for eye color variations with minor effects (Liu et al., 2009). The first forensic DNA phenotyping panel for predicting eye color, IrisPlex system (Walsh et al., 2011), was developed based on a previous study from Liu et al. (2009). The IrisPlex system includes a multiplex panel of the six most informative eye color SNPs on six different genes (rs12913832 in HERC2, rs 1800407 in $O C A i 2$, rs 12896399 in SLC24A4, rs 16891982 in SLC45A2, rs 1393350 in TYR, and rs12203592 in IRF4) for predicting eye color. These SNPs can be genotyped 
using SNaPshot chemistry and capillary electrophoresis (Walsh et al., 2011). Eye color prediction system has been developed based on a multinominal logistic regression (MLR) that estimates probabilities for blue, brown, and intermediate (green-hazel) eye color using genotype and phenotype information from previously defined European population databases. This tool allows prediction of eye color from complete and partial genotype profiles. The prediction accuracy of the blue and brown eye color could be achieved over $90 \%$ but $70 \%$ accuracy is determined for intermediate eye color inference (Walsh et al., 2011; Chaitanya et al., 2014; Bulbul et al., 2020).

In forensic science, the biological samples encountered are often degraded or found in low amounts. DNA damage occurs due to the environmental conditions such as UV light, ionizing radiation, timing and genotoxic chemicals. UV radiation causes damage and mutations on DNA. Shorter wavelength UV hight such as UVC (100$280 \mathrm{~nm}$ ) degrade DNA at a faster rate due to the higher amount of energy expended (Grskovic et al., 2013; Hall et al., 2014). Degraded samples or biological samples that contain limited DNA (shed hairs, bone, teeth) can be through problematic for analysis of standard STRs show better performance with SNPs. The IrisPlex system is suitable for the analysis of degraded samples by the sensitivity threshold of $31 \mathrm{pg}$ of starting genomic DNA template (Walsh et al., 2011; Chaitanya et al., 2017).

The objective of this study was to determine the effect of type degradated DNA samples on prediction accuracy of the IrisPlex system.

\section{MATERIALS AND METHODS}

We collected blood and saliva samples from ten unrelated healthy donors from Istanbul, Turkey with written informed consent. This study was approved by the Ethics Committee of the Istanbul University Cerrahpasa Medicine Faculty, Istanbul, Turkey (No. 83045809/87). The observed phenotypes from volunteers were one blue, four brown and five hazel-green (intermediate) eye colors. We also photographed eye of the each participating individual.

After collection of the blood samples, the blood was dispensed on sterile linen fabric and allowed to dry at room temperature. Dried bloodstains were stored in an open box at room temperature for five years. Genomic DNA was extracted from bloodstain samples using a QIAamp DNA Mini Kit (Qiagen) according to the DNA Purification from Dried Blood Spots protocol. DNA samples were stored at $-20^{\circ} \mathrm{C}$ until PCR amplification.

DNA was extracted from buccal swab samples as soon as possible after the collection (within $24 \mathrm{~h}$ ) of samples. Buccal swab DNA extraction was made using a QIAamp DNA Mini Kit (Qiagen) according to the Buccal Swab protocol and DNA samples were stored at $-20^{\circ} \mathrm{C}$ until use. We used these DNA samples for UV degradation. Randomly selected five DNA samples (each $10 \mu$ l) were put in a sterile eppendorf tube and exposed to $253,7 \mathrm{~nm}$ UVC light (Grant-bio UVT-B-AR) for 30 and $60 \mathrm{~min}$. All DNA samples were quantified by Qubit fluorometer using the Quant-iT ${ }^{\mathrm{TM}}$ HS dsDNA HS Assay kit (Invitrogen).

We designed PCR and single-base extension (SBE) primers for the six eye color SNPs (rs12913832, rs1800407, rs12896399, rs16891982, rs1393350 and rs12203592) in IrisPlex panel as previously described (Walsh et al., 2011). We applied a primary multiplex PCR followed by a multiplex SBE using the SNaPshot kit (Thermo Fischer Scientific) as recommended by Walsh et al. (2011). The multiplex PCR amplification of these SNPs were adjusted PCR with a total volume of $10 \mu \mathrm{L}$ and contained 2X Qiagen Multiplex Master Mix, PCR primer mix, DNA (0,5- $2 \mathrm{ng})$ and nuclease-free water. PCR was performed using a GeneAmp 9700 thermal cycler (Thermo Fischer Scientific) with the suggested program (Walsh et al., 2011). Amplified fragments $(2,5 \mu \mathrm{l})$ are treated with the $1 \mu \mathrm{L}$ ExoSAP-IT (GE Healthcare) and are incubated at $37^{\circ} \mathrm{C}$ for 45 minutes followed by enzyme inactivation at $85^{\circ} \mathrm{C}$ for 15 minutes. SBE was performed in a total reaction volume of $5 \mu \mathrm{l}$ as described in (Walsh et al., 2011). After the SBE reactions, the products were cleaned of extra primers by using FastAP Thermosensitive Alkaline Phosphatase (Thermo Fischer Scientific).

The final products were separated and detected by capillary electrophoresis using an ABI Prism 310 Genetic Analyzer (Thermo Fischer Scientific) with $36 \mathrm{~cm}$ capillary arrays and POP4 polymer. Genotypes were determined with GeneMapper ID 3.1.2 analysis software (Thermo Fischer Scientific).

Eye color prediction was assessed with IrisPlex online prediction tool (https://hirisplex.erasmusmc.nl/) that uses a probability threshold of 0.7 (Walsh et al., 2011). Probability values for each sample were created for three categories blue, intermediate and brown. The category with the highest prediction probability value $(p>0.7)$ is determined as the most probable eye color. The probability values below 0.7 were marked as undefined.

\section{RESULTS}

First we determined the locations of 6 SNPs (rs1800407, rs16891982, rs12203592, rs12913832, rs1393350, rs12896399) in the capillary electrophoresis via singleplex reactions. Then multiplex reaction is prepared with equal primer concentrations. The ideal 
profile was created by increasing or decreasing the primer concentrations. A sample (9947A positive control) electropherogram of the optimized IrisPlex assay is illustrated in Figure 1.

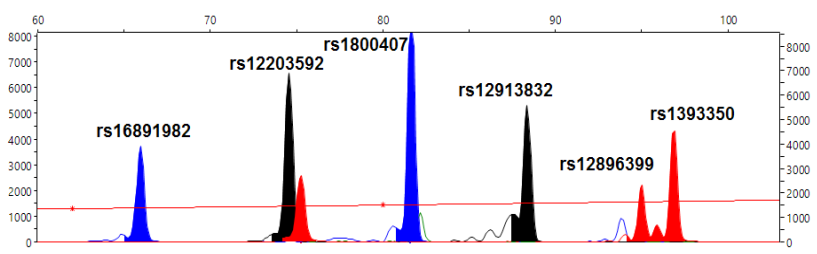

Fig. 1. A representative electropherogram of the optimized IrisPlex assay.

After optimization, all samples are genotyped and they are given in Table I. We refer to the samples without any degradation as the reference samples through the text. Complete profiles were obtained from all reference DNA samples. The four partial profiles (D02, D03, D06 and D08) were obtained from bloodstain samples stored for five years. For the sample "D02-5 years", we observed one locus lost at rs1393350 (CC>NN), two allele drop- outs at rs12203592 (CT>CN) and rs1800407 (GA> GN) with respect to the reference profile. For the sample "D035 years", we detected one allele drop-out at rs12203592 $(\mathrm{CT}>\mathrm{CN})$. For the samples "D06-5 years and D08-5 years", the loci loss was observed at rs $1393350(\mathrm{CC}>\mathrm{NN})$.

Then, the effects of UVC exposure on DNA samples were determined. Full profiles were obtained with $30 \mathrm{~min}$ and 60 min UVC exposure for D01, D04 and D05 samples. However, there was a significant loss of alleles and allele drop-outs were observed at D02 and D03 samples (Table I). We detected two allele drop-outs on rs12913832 $(\mathrm{CT}>\mathrm{CN})$ and $\mathrm{rs} 12203592(\mathrm{CT}>\mathrm{CN})$ at D02 sample for the $60 \mathrm{~min}$ UVC exposure time. Allele drop-out at rs12203592 $(\mathrm{CT}>\mathrm{CN})$ loci was also observed for D03 sample for the 60 min UVC exposure time. For the 30 min UVC exposure time rs1800407 (GA> GN) loci was incomplete for D02 and D03 samples (Table I).

According to those findings, the effect of degradation is observed to vary on UVC exposed and aged bloodstains samples. D02 and D03 were significantly more degraded than other samples. The observed profile for D02 is shown in Figure 2.

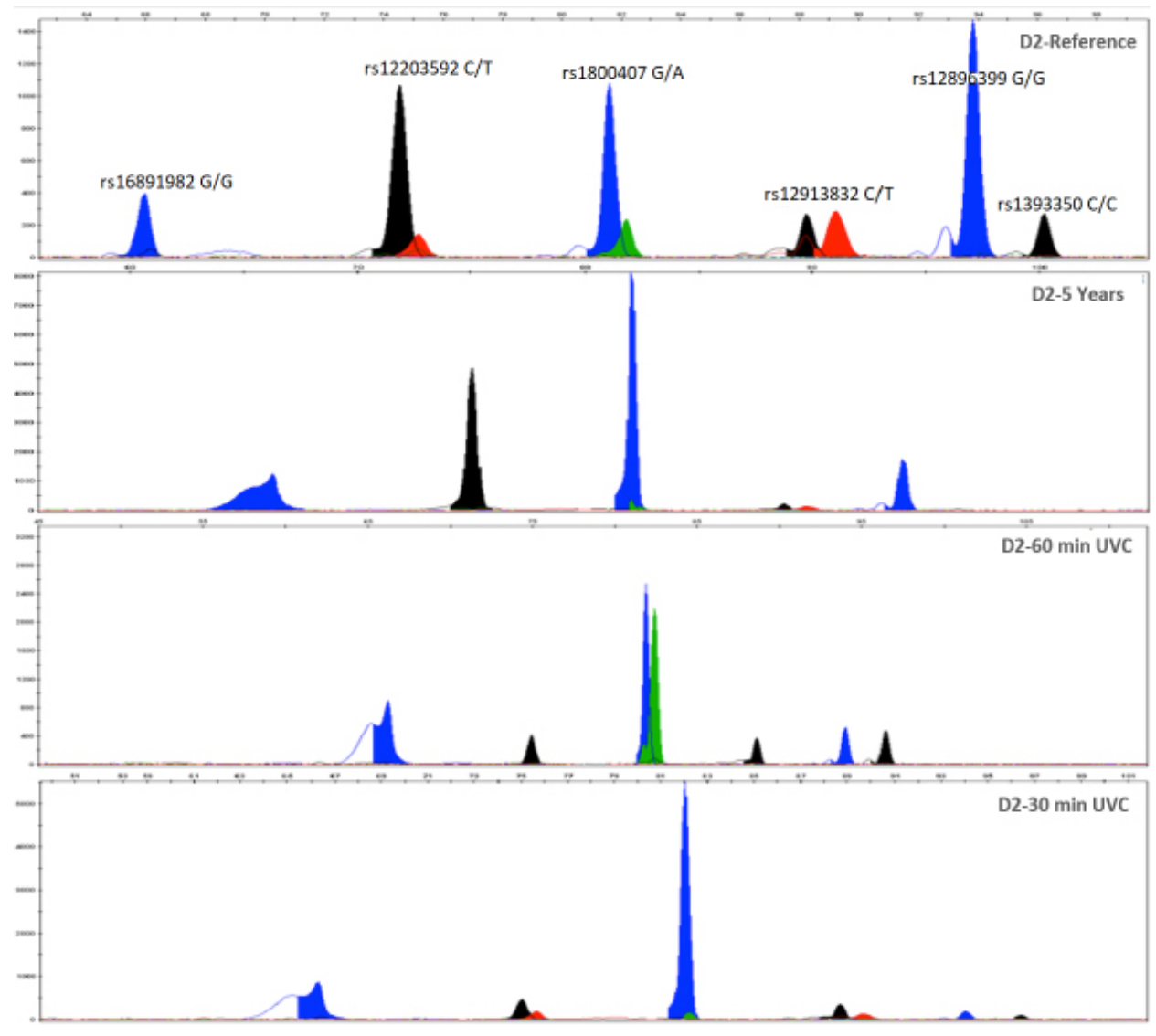

Fig. 2. The electropherogram results of the D02 reference, 5 years old bloodstain, 30 min and 60 min UVC-exposed samples. 
Table I. Genotypes of the all samples.

\begin{tabular}{|c|c|c|c|c|c|c|}
\hline Gene/ & HERC2 & OCA2 & SLC2A4 & SLC45A2 & TYR & IRF4 \\
\hline rs-code/ & rs12913832 & rs1800407 & rs12896399 & rs16891982 & rs1393350 & rs12203592 \\
\hline Alleles & $\mathrm{C} / \mathrm{T}$ & G/A & $T / G$ & $\mathrm{G} / \mathrm{C}$ & $\mathrm{C} / \mathrm{T}$ & $\mathrm{C} / \mathrm{T}$ \\
\hline \multicolumn{7}{|l|}{ Samples } \\
\hline D01-reference & TT & GG & GG & GG & $\mathrm{CC}$ & $\mathrm{CC}$ \\
\hline D01-5 years & TT & GG & GG & GG & $\mathrm{CC}$ & $\mathrm{CC}$ \\
\hline D01-60 min UV & TT & GG & GG & GG & $\mathrm{CC}$ & $\mathrm{CC}$ \\
\hline D01-30 min UV & TT & GG & GG & GG & $\mathrm{CC}$ & $\mathrm{CC}$ \\
\hline D02-reference & CT & GA & GG & GG & $\mathrm{CC}$ & CT \\
\hline D02-5 years & CT & $G N$ & GG & GG & $N N$ & $C N$ \\
\hline D02-60 min UV & $C N$ & GA & GG & GG & $\mathrm{CC}$ & $C N$ \\
\hline D02-30 min UV & $\mathrm{CT}$ & $G N$ & GG & GG & $\mathrm{CC}$ & СT \\
\hline D03- reference & CT & GA & GG & GG & $\mathrm{CC}$ & CT \\
\hline D03-5 years & CT & GA & GG & GG & $\mathrm{CC}$ & $C N$ \\
\hline D03-60 min UV & CT & GA & GG & GG & $\mathrm{CC}$ & $C N$ \\
\hline D03-30 min UV & СT & $G N$ & GG & GG & $\mathrm{CC}$ & СТ \\
\hline D04- reference & CT & GG & GT & GG & $\mathrm{CC}$ & $\mathrm{CC}$ \\
\hline D04-5 years & СТ & GG & GT & GG & $\mathrm{CC}$ & $\mathrm{CC}$ \\
\hline D04-60 min UV & CT & GG & GT & GG & $\mathrm{CC}$ & $\mathrm{CC}$ \\
\hline D04-30 min UV & СТ & GG & GT & GG & $\mathrm{CC}$ & $\mathrm{CC}$ \\
\hline D05- reference & TT & GG & GT & $\mathrm{GC}$ & $\mathrm{CC}$ & CT \\
\hline D05-5 years & TT & GG & GT & $\mathrm{GC}$ & $\mathrm{CC}$ & СT \\
\hline D05-60 min UV & TT & GG & GT & $\mathrm{GC}$ & $\mathrm{CC}$ & CT \\
\hline D05-30 $\min$ UV & TT & GG & GT & $\mathrm{GC}$ & $\mathrm{CC}$ & СТ \\
\hline D06- reference & $\mathrm{CC}$ & GG & GG & GG & $\mathrm{CC}$ & $\mathrm{CC}$ \\
\hline D06-5 years & $\mathrm{CC}$ & GG & GG & GG & $N N$ & $\mathrm{CC}$ \\
\hline D07- reference & TT & GA & GG & GG & $\mathrm{CC}$ & $\mathrm{CC}$ \\
\hline D07-5 years & TT & GA & GG & GG & $\mathrm{CC}$ & $\mathrm{CC}$ \\
\hline D08- reference & TT & GG & GG & GG & $\mathrm{CC}$ & $\mathrm{CC}$ \\
\hline D08-5 years & TT & GG & GG & GG & $N N$ & $\mathrm{CC}$ \\
\hline D09- reference & CT & GG & GT & GG & CT & $\mathrm{CC}$ \\
\hline D09-5 years & CT & GG & GT & GG & СT & $\mathrm{CC}$ \\
\hline D10- reference & CT & GG & GG & $\mathrm{GC}$ & $\mathrm{CC}$ & $\mathrm{CC}$ \\
\hline D10-5 years & $\mathrm{CT}$ & GG & GG & $\mathrm{GC}$ & $\mathrm{CC}$ & $\mathrm{CC}$ \\
\hline
\end{tabular}

$* \mathrm{~N}$ refers to allele drop-outs.

To further illustrate the predictive performance of the IrisPlex assay on degraded samples, we used an online IrisPlex prediction tool for the estimation of the three eye color phenotypes (blue, brown and intermediate) (Walsh et al., 2011). Table II represents the predictions of the eye color for all samples. The table is ordered based on sample name, eye images, actual and predicted eye colors and prediction probabilities for all three eye color categories provided for each sample.
The eye color predictions of the all brown (D01, D05, D08 and D10) individuals and one blue (D06) individual were fully agreed with the eye color phenotype from visual inspection for reference and degraded samples. Although individuals D06 and D08 had lost rs1393350 (Table I) loci at five-year stored bloodstain samples, the eye color prediction values slightly drop $(0,986$ to 0,985 for D08 and 0,065 to 0,055 ) therefore having no effect on the final predictions. 
Table II. The eye color prediction results of ten individuals after applying IrisPlex assay. The highest of the three prediction probabilities per individual is highlighted in bold and italic. The area in red marks (D2 and D3 individuals) with unclassified or non-conclusive eye color prediction results based on the IrisPlex test applied.

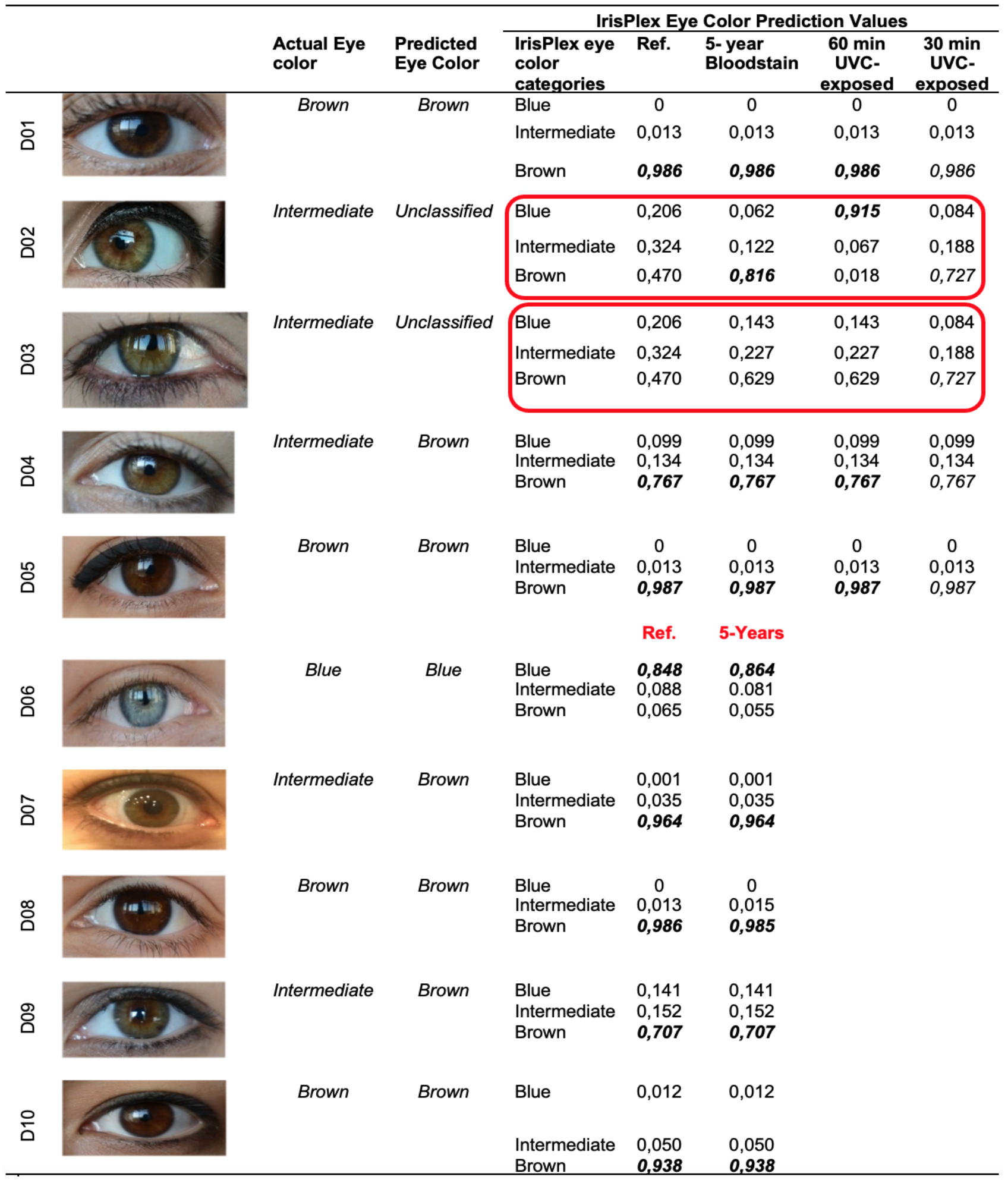


Three intermediate (hazel-green) eye colored individuals (D04, D07 and D09) were predicted more like to be brown eye color with a probability threshold of 0.7 provided. It is important to note that the classification was incorrect for these individuals; however, the prediction values for individuals D04 $(0,767)$ and D09 $(0,707)$ were lower than actual brown eye colored individuals.

Only two individuals (D02 and D03 references) were below 0.7 cut-off probability threshold and unclassified into their categories by the IrisPlex prediction model. The degradations by aging bloodstains and UVC exposure are observed to have a significant effect on the prediction of these individuals. At D02 estimated category of the eye color is changed (brown) (Table II) when one locus was lost (rs1393350) and two allele drop-outs (rs12203592, rs180040) were occurred from the bloodstain samples stored for five years (Table I). D02 60 min UVC exposed sample is predicted as blue eye color (Table II) when two allele drop-outs on rs12913832 and rs12203592 are observed (Table I). For the D02 and D03 samples $30 \mathrm{~min}$ UVC exposure caused allele drop-out at rs1800407 loci and prediction is more like to be brown eye color. For D03 bloodstain sample stored for five years and $60 \mathrm{~min}$ UVC exposed sample had the same allele drop-out at rs12203592 (Table I) which resulted in prediction values below 0.7 and therefore the samples were unclassified.

\section{DISCUSSION}

DNA allows for the identification of the individual from biological samples found in a crime scene. However, identification can be challenging when the sample found is degraded or in low amounts. In such cases alternative DNA markers (SNPs, InDels e.g.) can be used to get clues regarding the ancestry, phenotype, lineage, and identity. One potential forensic application of SNP analysis is the determination of the externally visible characteristics such as hair and eye color of a given individual. These findings can reveal the physical characteristics of a person to provide leads for investigations (Valenzuela et al., 2010; Kayser, 2015, Maronas et al., 2015). In this study, we have tested IrisPlex eye color prediction system on old bloodstains and UVC exposed samples to determine how degradation affects the prediction accuracy of the eye color.

We found that a total of 8 out of 10 individuals' eye color prediction values were above the cut-off probability threshold ( $>0.7)$. Blue (D06 reference) and brown eyes (D01, D05, D08, D10 reference samples) were predicted accurately and inferred phenotypes were confirmed from self-reported and photographed eye colors (Table II).

The intermediate eye colors did not yield any correct prediction. Our sample set had three incorrect and two inconclusive results for intermediate eye color samples. The three intermediate eye colored individuals (D04, D07 and D09 reference samples) were estimated as brown. However, the prediction values for individuals D04 (prediction value for brown= 0,767) and D09 (prediction value for brown $=0,707$ ) were lower than other brown eye colored individuals. The other two intermediate eye colored individuals (D02 and D03 reference samples) were not classified because of the cut-off probability threshold. Therefore, our results confirm that the IrisPlex prediction system is a good choice for determining blue and brown eye colors with high accuracy, however, the system is shown to be unreliable for intermediate eye colors. These findings are consistent with what has been found in previous studies (Walsh et al., 2011; Dembinski and Picard, 2014; Freire-Aradas et al., 2014; Bulbul et al., 2020). Walsh et al. (2011) reported that the prediction values increase when the eye color of the individual gets darken (dark blue or dark brown) and thus there is a correlation between the predicted values and the visual determination of the eye color phenotypes. A similar pattern of results was obtained in our study for individuals D04 and D09. Moreover, additional informative SNPs associated with the intermediate color were published and tested for increasing accuracy and the HERC2 SNP rs1129038 appears promising SNP (Ruiz et al., 2013; Freire-Aradas et al., 2014; Bulbul et al., 2020).

We used bloodstains stored for five years and UVC exposed (30 and $60 \mathrm{~min}$ ) samples for determining the sensitivity and accuracy of the IrisPlex prediction system. We observed allele drop-outs and locus loss only at four (D02, D03, D06, and D08) old bloodstain samples (Table I). Although rs 1393350 locus was lost for D06 and D08 old bloodstain samples, these partial genotypes did not lead to erroneous eye color phenotype predictions. D03-bloodstain sample had a drop-out of the $\mathrm{T}$ allele at rs12203592 which increased the prediction value of the brown eye color. D02-bloodstain sample had a significant loss of alleles at several loci, which led to erroneous eye color prediction.

UV radiation is known to fragment DNA and we, therefore, tested IrisPlex system to assess the impact of DNA degradation on the eye color prediction accuracy. The UVC continuous exposure for 30 and $60 \mathrm{~min}$ to D01, D04, and D05 samples did not lead to any change in the genotypes of these samples. We obtained partial loss of genetic profile at D02 and D03 UVC exposed samples. The allele drop-out at rs1800407 at D02 30 min UVC exposed sample did not change the eye color prediction. When the UVC exposure up to $60 \mathrm{~min}$, there were allele 
drop-outs at HERC2 rs12913832 and IRF4 rs12203592 for the same sample which resulted in an erroneous eye color prediction. rs12913832 in the HERC2 gene is significantly linked with blue vs. brown eye color. The absence of this locus severely limits the prediction accuracy of the entire eye color (Walsh et al., 2011; Visser et al., 2012). Therefore, it is suggested that in case of the absence of this locus, the researchers should not report the results and perform multiple amplification of the sample to ensure consistency of genotyping (Chaitanya et al., 2014; Walsh and Kayser, 2016).

The limitations of the IrisPlex eye color prediction assay has been tested under different conditions (DrausBarini et al., 2013; Walsh et al., 2013; Chaitanya et al., 2014). Although IrisPlex assay provides a threshold of 31 pg sensitivity, the quality of the DNA from the degraded samples, as well as the environmental conditions (UV radiation, storage) influence the results. Our findings are in accordance with findings reported by (Draus-Barini et al., 2013; Walsh et al., 2013; Chaitanya et al., 2014, 2017). Obviously, low quantity and degraded samples are very challenging as expected for any other genotyping system (STRs, SNPs etc.), IrisPlex assay also has limitations for difficult DNA samples. Hence, to avoid incorrect classifications and to confirm the genotyping results, multiple amplification of the degraded samples are highly recommended. Moreover, when dealing with such difficult samples guidelines and recommendations that are settled previously should be followed precisely.

\section{ACKNOWLEDGEMENTS}

This study was supported by İstanbul University, Scientific Research Fund (Project No: 41343 and 26105).

\section{Ethical approval}

This study protocol was approved by ethical committee of the Istanbul University Cerrahpasa Medicine Faculty, Istanbul, Turkey (No. 83045809/87) and all the participants consented to use their genetic material and other necessary information.

Statement of conflict of interest

The authors have declared no conflict of interest.

\section{REFERENCES}

Budowle, B. and van Daal, A., 2008. Forensically relevant SNP classes. Biotechniques, 44: 603-608, 610. https://doi.org/10.2144/000112806

Bulbul, O., Zorlu, T. and Filoglu, G., 2020. Prediction of human eye colour using highly informative phenotype SNPs (PISNPs) Austral. J. Foren. Sci.. 52(1): 27-37. https://doi.org/10.1080/00450618.20 18.1484161

Chaitanya, L., Pajnic, I.Z., Walsh, S., Balazic, J., Zupanc, T. and Kayser, M., 2017. Bringing colour back after 70 years: Predicting eye and hair colour from skeletal remains of World War II victims using the HIrisPlex system. Foren. Sci. Int. Genet., 26: 4857. https://doi.org/10.1016/j.fsigen.2016.10.004

Chaitanya, L., Walsh, S., Andersen, J.D., Ansell, R., Ballantyne, K., Ballard, D., Banemann, R., Bauer, C.M., Bento, A.N., Brisighelli, F., Capal, T., Clarisse, L., Gross, T.E., Haas, C., Hoff-Olsen, P., Hollard, C., Keyser, C., Kiesler, K.M., Kohler, P., Kupiec, T., Linacre, A., Minawi, T., Morling, N., Nilsson, H., Norén, L., Ottens, R., Palo, J.U., Parson, W., Pascali, V.L., Phillips, C., Porto, M.J., Sajantila, A., Schneider, P.M., Sijen, T., Söchtig, J., Syndercombe-Court, D., Tillmar, A., Turanska, M., Vallone, P.M., Zatkalíková, L., Zidkova, A., Branicki, W. and Kayser, M., 2014. Collaborative EDNAP exercise on the IrisPlex system for DNAbased prediction of human eye colour. Foren. Sci. Int. Genet., 11: 241-251. https://doi.org/10.1016/j. fsigen.2014.04.006

Dembinski, G.M. and Picard, C.J., 2014. Evaluation of the IrisPlex DNA-based eye color prediction assay in a United States population. Foren. Sci. Int. Genet. 9: 111-117. https://doi.org/10.1016/j. fsigen.2013.12.003

Donnelly, M.P., Paschou, P., Grigorenko, E., Gurwitz, D., Barta, C., Lu, R.B., Zhukova, OV., Kim, J-J., Siniscalco, M., New, M., Li, H., Kajuna, S.L.B., Manolopoulos, V.G., Speed, W.C., Pakstis, A.J., Kidd, J.R. and Kidd, K.K., 2012. A global view of the OCA2-HERC2 region and pigmentation. Hum. Genet., 131: 683-696. https://doi.org/10.1007/ s00439-011-1110-x

Draus-Barini, J., Walsh, S., Pospiech, E., Kupiec, T., Glab, H., Branicki, W. and Kayser, M., 2013. Bona fide colour: DNA prediction of human eye and hair colour from ancient and contemporary skeletal remains. Investig. Genet., 4: 3. https://doi. org/10.1186/2041-2223-4-3

Freire-Aradas, A., Ruiz, Y., Phillips, C., Maronas, O., Sochtig, J., Tato, A.G., Álvarez, J., Casaresde, D.M., Silbigerc, C.V.N., Luchessic, A.D., Luchessid, C.A., Carracedoaf, M.A. and Lareua, M.V., 2014. Exploring iris colour prediction and ancestry inference in admixed populations of South America. Foren. Sci. Int. Genet., 13: 3-9. https:// doi.org/10.1016/j.fsigen.2014.06.007 
Frudakis, T., Terravainen, T. and Thomas, M., 2007. Multilocus OCA2 genotypes specify human iris colors Hum. Genet., 122: 311-326. https://doi. org/10.1007/s00439-007-0401-8

Grskovic, B., Zrnec, D., Popovic, M., Petek, M.J., Primorac, D. and Mrsic, G., 2013. Effect of ultraviolet $\mathrm{C}$ radiation on biological samples. Croat. med. J., 54: 263-271. https://doi.org/10.3325/ cmj.2013.54.263

Hall, A. and Ballantyne, J., 2004. Characterization of UVC-induced DNA damage in bloodstains: Forensic implications. Anal. Bioanal. Chem., 380: 72-83. https://doi.org/10.1007/s00216-004-2681-3

Hall, A., Sims, L.M. and Ballantyne, J., 2014. Assessment of DNA damage induced by terrestrial UV irradiation of dried bloodstains: Forensic implications. Foren. Sci. Int. Genet., 8: 24-32. https://doi.org/10.1016/j.fsigen.2013.06.010

Kayser, M., 2015. Forensic DNA Phenotyping: Predicting human appearance from crime scene material for investigative purposes. Foren. Sci. Int. Genet., 18: 33-48. https://doi.org/10.1016/j. fsigen.2015.02.003

Kayser, M. and de Knijff, P., 2011. Improving human forensics through advances in genetics, genomics and molecular biology. Nat. Rev. Genet., 12: 179192. https://doi.org/10.1038/nrg2952

Kayser, M. and Schneider, P.M., 2009. DNAbased prediction of human externally visible characteristics in forensics: motivations, scientific challenges, and ethical considerations. Foren. Sci. Int. Genet., 3: 154-161. https://doi.org/10.1016/j. fsigen.2009.01.012

Liu, F., Hendriks, A.E., Ralf, A., Boot, A.M., Benyi, E., Savendahl, L., Oostra, B.A., Duijn, C., Hofman, A., Rivadeneira, F., Uitterlinden, A.G., Drop, S.L.S. and Kayser, M., 2014. Common DNA variants predict tall stature in Europeans. Hum. Genet., 133: 587-597. https://doi.org/10.1007/s00439-0131394-0

Liu, F., van Duijn, K., Vingerling, J.R., Hofman, A., Uitterlinden, A.G., Janssens, A.C. and Kayser, M., 2009. Eye color and the prediction of complex phenotypes from genotypes. Curr. Biol., 19: R192193. https://doi.org/10.1016/j.cub.2009.01.027

Liu, F., Visser, M., Duffy, D.L., Hysi, P.G., Jacobs, L.C. and Lao, O., 2015. Genetics of skin color variation in Europeans: genome-wide association studies with functional follow-up. Hum. Genet., 134: 823835. https://doi.org/10.1007/s00439-015-1559-0

Maronas, O., Sochtig, J., Ruiz, Y., Phillips, C., Carracedo, A. and Lareu, M.V., 2015. The genetics of skin, hair, and eye color variation and its relevance to forensic pigmentation predictive tests. Foren. Sci. Rev., 27: 13-40.

Mehta, B., Daniel, R., Phillips, C. and McNevin, D., 2017. Forensically relevant $\mathrm{SNaPshot}(\mathrm{R})$ assays for human DNA SNP analysis: A review. Int. J. Legal. Med., 131: 21-37. https://doi.org/10.1007/ s00414-016-1490-5

Pospiech, E., Chen, Y., Kukla-Bartoszek, M., Breslin, K., Aliferi, A., Andersen, J.D., Ballard, D., Chaitanya, L., Freire-Aradas, A., van der Gaag, K. J., Giron-Santamaria, L., Gross, T. E., Gysi, M., Huber, G., Mosquera-Miguel, A., Muralidharan, C., Skowron, M., Carracedo, A., Haas, C., Morling, N., Parson, W., Phillips, C., Schneider, P. M., Sijen, T., Syndercombe-Court, D., Vennemann, M., Wu, S., Xu, S., Jin, L., Wang, S., Zhu, G., Martin, N. G., Medland, S. E., Branicki, W., Walsh, S., Liu, F., Kayser, M. and Consortium, E. U-N., 2018. Towards broadening Forensic DNA Phenotyping beyond pigmentation: Improving the prediction of head hair shape from DNA. Foren. Sci. Int. Genet., 37: 241-251. https://doi.org/10.1016/j. fsigen.2018.08.017

Ruiz, Y., Phillips, C., Gomez-Tato, A., Alvarez-Dios, J., Casares de Cal, M., Cruz, R., Maronas, O., Sochtig, J., Fondevila, M., Rodriguez-Cid, M.J., Carracedo, A. and Lareu, M.V., 2013. Further development of forensic eye color predictive tests. Foren. Sci. Int. Genet., 7: 28-40. https://doi.org/10.1016/j. fsigen.2012.05.009

Shriver, M.D., Parra, E.J., Dios, S., Bonilla, C., Norton, H., Jovel, C., Pfaff, C., Jones, C., Massac, A., Cameron, N., Baron, A., Jackson, T., Argyropoulos, G., Jin, L., Hoggart, C.J., McKeigue, P.M. and Kittles, R.A., 2003. Skin pigmentation, biogeographical ancestry and admixture mapping. Hum. Genet., 112: 387-399. https://doi.org/10.1007/ s00439-002-0896-y

Sturm, R.A., 2009. Molecular genetics of human pigmentation diversity. Hum. mol. Genet., 18: R917. https://doi.org/10.1093/hmg/ddp003

Sulem, P., Gudbjartsson, D.F., Stacey, S.N., Helgason, A., Rafnar, T., Magnusson, K.P., Manolescu, A., Karason, A., Palsson, A., Thorleifsson, G., Jakobsdottir, M., Steinberg, S., Palsson, S., Jonasson, F., Sigurgeirsson, B., Thorisdottir, K., Ragnarsson, R., Benediktsdottir, K.R., Aben, K.K., Kiemeney, L.A., Olafsson, J.H., Gulcher, J., Kong, A., Thorsteinsdottir, U. and Stefansson, K., 2007. Genetic determinants of hair, eye and skin pigmentation in Europeans. Nat. Genet., 39: 1443- 
1452. https://doi.org/10.1038/ng.2007.13

Toom, V., Wienroth, M., M'Charek, A., Prainsack, B., Williams, R., Duster, T., Heinemann, T., Kruse, C., Machado, H. and Murphy, E., 2016. Approaching ethical, legal and social issues of emerging forensic DNA phenotyping (FDP) technologies comprehensively: Reply to 'Forensic DNA phenotyping: Predicting human appearance from crime scene material for investigative purposes' by Manfred Kayser. Foren. Sci. Int. Genet., 22: e1-e4. https://doi.org/10.1016/j.fsigen.2016.01.010

Valenzuela, R.K., Henderson, M.S., Walsh, M.H., Garrison, N.A., Kelch, J.T., Cohen-Barak, O., Erickson, D.T., John Meaney, F., Bruce Walsh, J., Cheng, K.C., Ito, S., Wakamatsu, K., Frudakis, T., Thomas, M. and Brilliant, M.H., 2010. Predicting phenotype from genotype: normal pigmentation. $J$. Foren. Sci., 55: 315-322. https://doi.org/10.1111/ j.1556-4029.2009.01317.x

Visser, M., Kayser, M. and Palstra, R.J., 2012. HERC2 rs12913832 modulates human pigmentation by attenuating chromatin-loop formation between a long-range enhancer and the OCA2 promoter. Genome Res., 22: 446-455. https://doi.org/10.1101/ gr.128652.111

Walsh, S., Chaitanya, .L, Breslin, K., Muralidharan, C., Bronikowska, A., Pospiech, E., Koller, J., Kovatsi, L., Wollstein, A., Branicki, W., Liu, F. and Kayser, M., 2017. Global skin colour prediction from DNA. Hum Genet. 136(7): 847-863. https://doi. org/10.1007/s00439-017-1808-5

Walsh, S. and Kayser, M., 2016. A practical guide to the HIrisPlex system: Simultaneous prediction of eye and hair color from DNA. Meth. Mol. Biol., 1420: 213-231. https://doi.org/10.1007/978-1-49393597-0_17

Walsh, S., Liu, F., Ballantyne, K.N., van Oven, M., Lao, O. and Kayser, M., 2011. IrisPlex: A sensitive DNA tool for accurate prediction of blue and brown eye colour in the absence of ancestry information. Foren. Sci. Int. Genet., 5: 170-180. https://doi. org/10.1016/j.fsigen.2010.02.004

Walsh, S., Liu, F., Wollstein, A., Kovatsi, L., Ralf, A., Kosiniak-Kamysz, A., Branicki, W. and Kayser, M., 2013. The HIrisPlex system for simultaneous prediction of hair and eye colour from DNA. Foren. Sci. Int. Genet., 7: 98-115. https://doi. org/10.1016/j.fsigen.2012.07.005 